\title{
Maternal and Infant Characteristics and Outcomes Among Women With Confirmed or Presumed COVID-19 During Pregnancy: 14 States and the District of Columbia
}

\author{
Joyce A. Martin, M.P.H., Michelle J.K. Osterman, M.H.S., and Claudia P. Valenzuela, M.P.H., \\ Division of Vital Statistics
}

\section{Abstract}

\begin{abstract}
Objectives-This report describes characteristics and selected pregnancy outcomes among mothers with and without confirmed or presumed COVID-19 during pregnancy by maternal age, educational attainment, race and Hispanic origin, and source of payment for the delivery for a 14-state and District of Columbia (D.C.) reporting area.
\end{abstract}

Methods-Data are based on supplemental reports of presumed or confirmed COVID-19 cases occurring at any time during pregnancy provided to the National Center for Health Statistics by 14 states and D.C. between April 2020 and April 2021 and linked to the U.S. Standard Certificate of Live Birth. Comparisons are made between mothers with COVID-19 and mothers without COVID-19 on selected maternal characteristics (age, educational attainment, race and Hispanic origin, and source of payment for the delivery) and pregnancy outcomes (admission to an intensive care unit [ICU], preterm and low birthweight [LBW] births, and admission to a neonatal intensive care unit [NICU]).

Results-In the 15-jurisdiction reporting area from April 2020 through April 2021, mothers reported to have had COVID-19 during pregnancy tended to be younger and have lower educational levels than mothers who did not have COVID-19. Mothers with COVID-19 were more likely to be Hispanic or
non-Hispanic Black and to have Medicaid as the principal source of payment for the delivery. Overall, and generally among each of the age, education, source of payment, and race and Hispanic-origin groups, mothers who had COVID-19 during pregnancy were more likely to be admitted to an ICU, and to have an infant born preterm, LBW, and admitted to a NICU than mothers who did not have COVID-19.

Keywords: birth certificate ICU • preterm birth $\bullet$ low birthweight $\bullet$ NICU

\section{Introduction}

Information on Coronavirus (COVID-19) is not included on the U.S. Standard Certificate of Live Birth (1). In April 2020, as the need for information on the public health impact of COVID-19 became evident, the National Center for Health Statistics (NCHS) began working with its state vital statistics partners to develop approaches for the collection of data on COVID-19 during pregnancy and the sharing of this information with NCHS independent of the standard birth data reporting process. Between April and June 2020, a total of 14 states and the District of Columbia (D.C.), representing $27 \%$ of all U.S. live births, began reporting cases of confirmed or presumed COVID-19 during pregnancy to NCHS (2). This information was linked to the U.S. Standard Certificate of Live Birth, allowing for the analysis of several maternal and infant characteristics and pregnancy outcomes that may be associated with COVID-19 during pregnancy (2). Although the maternal COVID-19 data collected are not representative of all U.S. births and have other limitations, linkage of COVID-19 cases with birth certificate data provides unique information on COVID-19 in pregnant women.

This report describes characteristics and selected pregnancy outcomes among mothers with and without confirmed or presumed COVID-19 during pregnancy by maternal age, educational attainment, race and Hispanic origin, and source of payment for the delivery for a 14-state and D.C. reporting area.

\section{Methods}

This analysis is based on reports of presumed or confirmed COVID-19 cases occurring at any time during pregnancy and provided to NCHS by 14 states (Alabama, Alaska, Arkansas, California, Idaho, Maine, Maryland, New Hampshire, North Dakota, Ohio, Oklahoma, Oregon, Tennessee, and West Virginia) and D.C. between April 2020 and April 2021. The data file was created on June 17, 2021, when information on maternal COVID-19 became available for all reporting areas for the April 2020 through April 2021 time period. Supplemental information on maternal COVID-19, which is not included on the U.S. Standard Certificate of Live Birth, is sent by the jurisdictions to NCHS independent of the standard birth data transmission process and then linked to birth records by NCHS. Nearly all cases of maternal COVID-19 reported 
to NCHS $(23,389$ or $99.6 \%)$ were linked to the corresponding birth record, which contains detailed information on the mother and the newborn. Unlinked cases are those for which the standard birth record had not been received by NCHS at the time of linkage.

Not all 15 reporting areas provided information for the total reporting period. Beginning in April 2020, 8 states and D.C. reported maternal COVID-19 cases to NCHS. In May 2020, a total of 10 states and D.C. were reporting cases and by June 2020, a total of 14 states and D.C. were reporting cases. All 15 reporting areas were reporting information on maternal COVID-19 status by June 19, 2020 (2).

Births occurring in these 15 vital statistics jurisdictions represent $27 \%$ of all births reported to NCHS during April 2020-April 2021. Characteristics of the reporting area are a function of the participating jurisdictions and the length of time that they have been reporting and are not generalizable to the United States as a whole. For example, California accounted for $39.5 \%$ of births occurring in the 15 -jurisdiction reporting area, while California accounted for only $11.5 \%$ of U.S. births overall. Slight differences in the distribution of births by race and Hispanic origin were seen when comparing the 15 reporting areas with the United States overall. Specifically, the 15 reporting areas had a slightly larger percentage of Hispanic (25.6\% compared with $24.1 \%$ ) and non-Hispanic Asian (7.3\% compared with $6.0 \%$ ) births than the total United States, and a smaller percentage of non-Hispanic White (50.2\% compared with 51.9\%) and non-Hispanic Black (12.7\% compared with $14.6 \%$ ) births.

The reporting jurisdictions have varying approaches to capturing information on maternal COVID-19. These approaches include adding an item on maternal COVID-19 to the state birth certificate, linking information from electronic disease surveillance systems to the birth record, and collecting special reports on maternal COVID-19 status from birthing hospitals. Whereas 10 states and D.C. capture both presumed and confirmed cases of COVID-19, 4 states (Maryland, North Dakota, Ohio, and Tennessee) capture confirmed cases only. California reports cases of presumed or confirmed maternal COVID-19; however, an issue was identified in the reporting of presumed cases and only confirmed cases of maternal COVID-19 are included for California in this report. There is likely an undercount of maternal COVID-19 cases, particularly in states for which only confirmed cases of COVID-19 are reported. For more detailed information on reporting methods by state, see reference 2 .

Birth certificate data are provisional and based on all birth records for the 15-jurisdiction reporting area for April 2020 through April 2021 received and processed by NCHS as of June 17, 2021 $(N=933,110)$. These records represent $99.9 \%$ of registered births for the reporting area (3).

Educational attainment of the mother is the highest degree or level of school completed by the mother at the time of birth and is self-reported. The education categories shown in this report are: less than a high school diploma, high school graduate or GED, some college but no degree, associate's degree, and bachelor's degree or higher. Educational attainment was missing for $3.1 \%$ of all records.

Race and Hispanic origin are reported independently on the birth certificate and are self-reported by the mother. Race of the mother was missing for $8.0 \%$ of births in the 15-jurisdiction area over the reporting period. Race of mother is imputed to the race of the father where known, or that of a preceding record with known race. Hispanic origin was missing for $4.3 \%$ of records. Data shown by Hispanic origin include all people of Hispanic origin of any race. Data for non-Hispanic people are shown separately for each single-race group. The tables and figures in this report show data for the categories of non-Hispanic, single-race White; non-Hispanic, single-race Black; non-Hispanic, single-race Asian; and Hispanic (for brevity in text, references to the race groups omit the term "single-race.")

Two principal sources of payment for the delivery are presented: a) Medicaid, which includes comparable state programs, and b) private insurance (such as BlueCross BlueShield or Aetna). Together, these two sources of payment account for more than $90 \%$ of births in the reporting area. The remaining sources of payment are grouped together and include self-pay, Indian Health Service, CHAMPUS or TRICARE, other government (federal, state, or local), or charity. Source of payment information was missing for $0.4 \%$ of records.

The pregnancy outcomes presented in the report are: intensive care unit (ICU) admission, preterm birth, low birthweight (LBW), and neonatal intensive care unit (NICU) admission. ICU admission is defined as admission of the mother to an intensive care unit. Preterm includes births at less than 37 weeks of gestation; gestational age is in completed weeks and based on the obstetric estimate of gestation. LBW includes infants born at less than 2,500 grams, and NICU admission is admission of the newborn to a neonatal intensive care unit. Information on ICU admission, gestational age, and birthweight was missing for $0.1 \%$ of records, and NICU admission for $0.2 \%$ of records. For detailed definitions of these items, see "Guide to completing the facility worksheets for the Certificate of Live Birth and Report of Fetal Death" (4). Tabulated data on the maternal and infant characteristics and pregnancy outcomes presented in this report (excluding births to non-Hispanic Asian mothers) and on demographic and maternal characteristics by maternal COVID-19 status are updated bimonthly (2).

The terms "maternal COVID-19" and "mothers with COVID-19" are used throughout the report to refer to women who were reported to have presumed or confirmed COVID-19 at any time during pregnancy.

Changes and differences presented in this report are statistically significant at 
the 0.05 level based on a two-tailed $z$ test, unless noted otherwise.

\section{Results}

\section{Maternal characteristics}

\section{Age}

- In the 15 -jurisdiction reporting area, mothers with COVID-19 were younger than mothers without COVID-19 (Table 1, Figure 1). For example, $28.0 \%$ of mothers with COVID-19 were under age 25 compared with $22.5 \%$ of mothers without COVID-19. Conversely, $15.8 \%$ of mothers with COVID-19 were aged 35 and over compared with $20.0 \%$ of mothers without COVID-19. Similar patterns were observed across all race and Hispanic-origin groups.

\section{Educational attainment}

- Mothers with COVID-19 tended to have lower levels of educational attainment than mothers without COVID-19 (Table 1, Figure 2).

For example, among mothers with COVID-19, 47.7\% had a high school diploma or less compared with $38.2 \%$ of mothers without COVID-19; $23.0 \%$ of mothers with COVID-19 had a bachelor's degree or higher compared with $33.8 \%$ of mothers without COVID-19. Patterns were generally similar across all race and Hispanic-origin groups.

\section{Race and Hispanic origin}

- Distributions of births by race and Hispanic origin differed by maternal COVID-19 status (Table 1, Figure 3). Among all mothers with COVID-19, 39.9\% were non-Hispanic White, 15.2\% were non-Hispanic Black, $3.4 \%$ were non-Hispanic Asian, and $34.2 \%$ were Hispanic. Conversely, among all mothers without COVID-19, 49.9\% were non-Hispanic White, 12.2\% were non-Hispanic Black, $7.3 \%$ were non-Hispanic Asian, and $24.7 \%$ were Hispanic.

Figure 1. Maternal COVID-19 status, by age of mother: 14 states and the District of Columbia, April 2020-April 2021

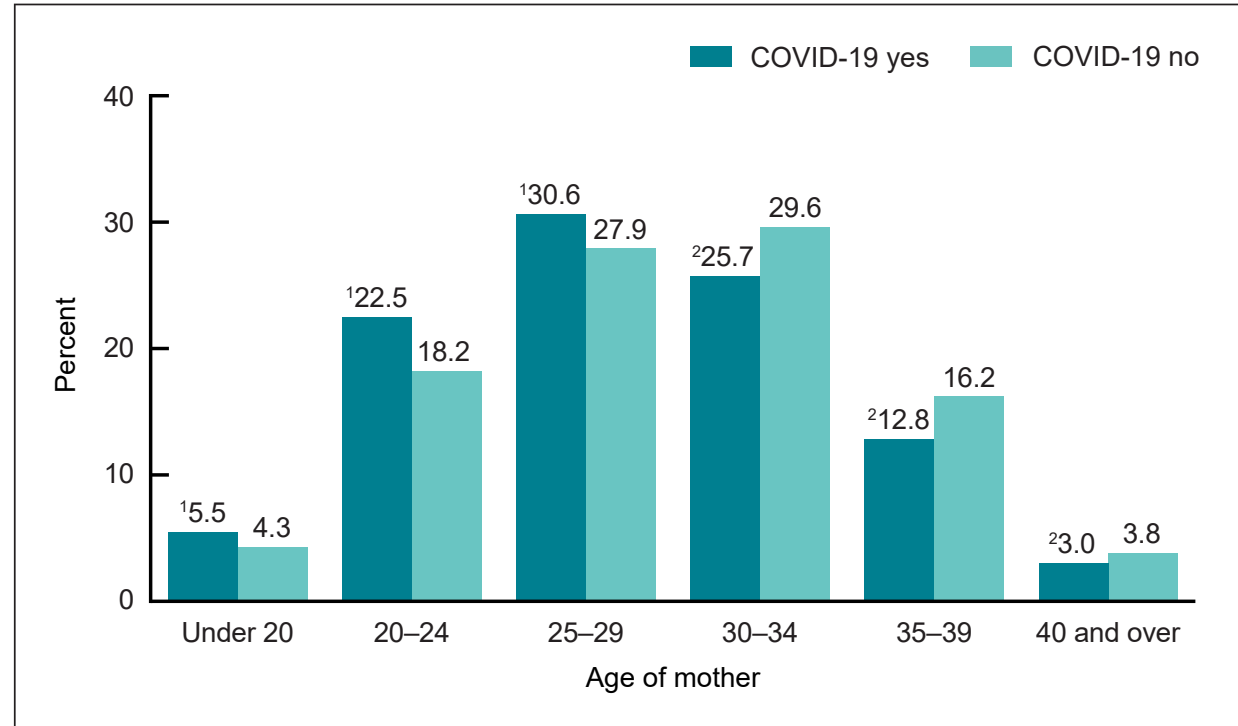

${ }^{1}$ Significantly higher than COVID-19 no $(p<0.05)$.

${ }^{2}$ Significantly lower than COVID-19 no $(p<0.05)$

NOTES: Reporting area includes Alabama, Alaska, Arkansas, California, District of Columbia, Idaho, Maine, Maryland, New Hampshire North Dakota, Ohio, Oklahoma, Oregon, Tennessee, and West Virginia. COVID-19 yes includes presumed or confirmed cases. SOURCE: National Center for Health Statistics, National Vital Statistics System, Natality.

Figure 2. Maternal COVID-19 status, by educational attainment and source of payment for the delivery: 14 states and the District of Columbia, April 2020-April 2021

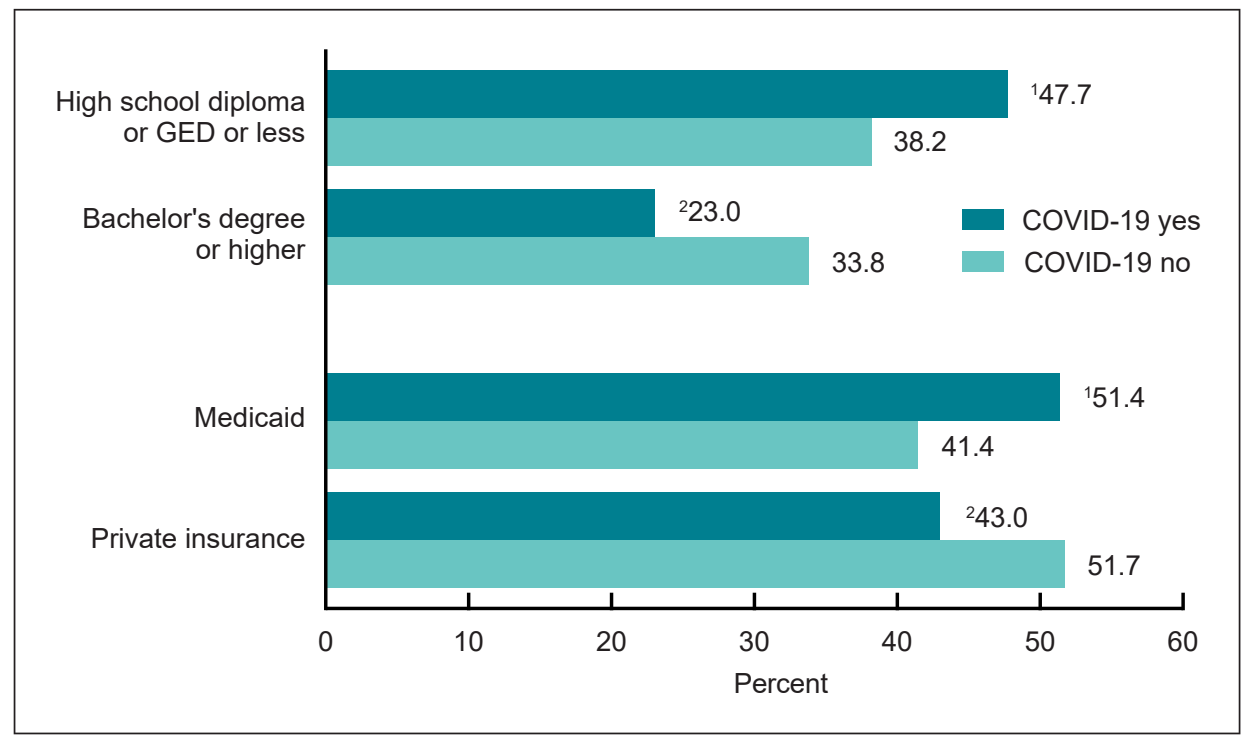

'Significantly higher than COVID-19 no $(p<0.05)$

2Significantly lower than COVID-19 no $(p<0.05)$.

NOTES: Reporting area includes Alabama, Alaska, Arkansas, California, District of Columbia, Idaho, Maine, Maryland, New Hampshire, North Dakota, Ohio, Oklahoma, Oregon, Tennessee, and West Virginia. COVID-19 yes includes presumed or confirmed cases. SOURCE: National Center for Health Statistics, National Vital Statistics System, Natality.

\section{Source of payment for the delivery}

- Medicaid was the principal source of payment for the delivery for just over one-half (51.4\%) of mothers with COVID-19 compared with $41.4 \%$ of mothers without COVID-19
(Table 1, Figure 2). Private insurance was the source for $43.0 \%$ of mothers with COVID-19 compared with 51.7\% without COVID-19.

- Medicaid was more likely to be the source of payment for mothers with COVID-19 than mothers without COVID-19 for all race and 
Figure 3. Distribution of births, by race and Hispanic origin and maternal COVID-19 status: 14 states and the District of Columbia, April 2020-April 2021

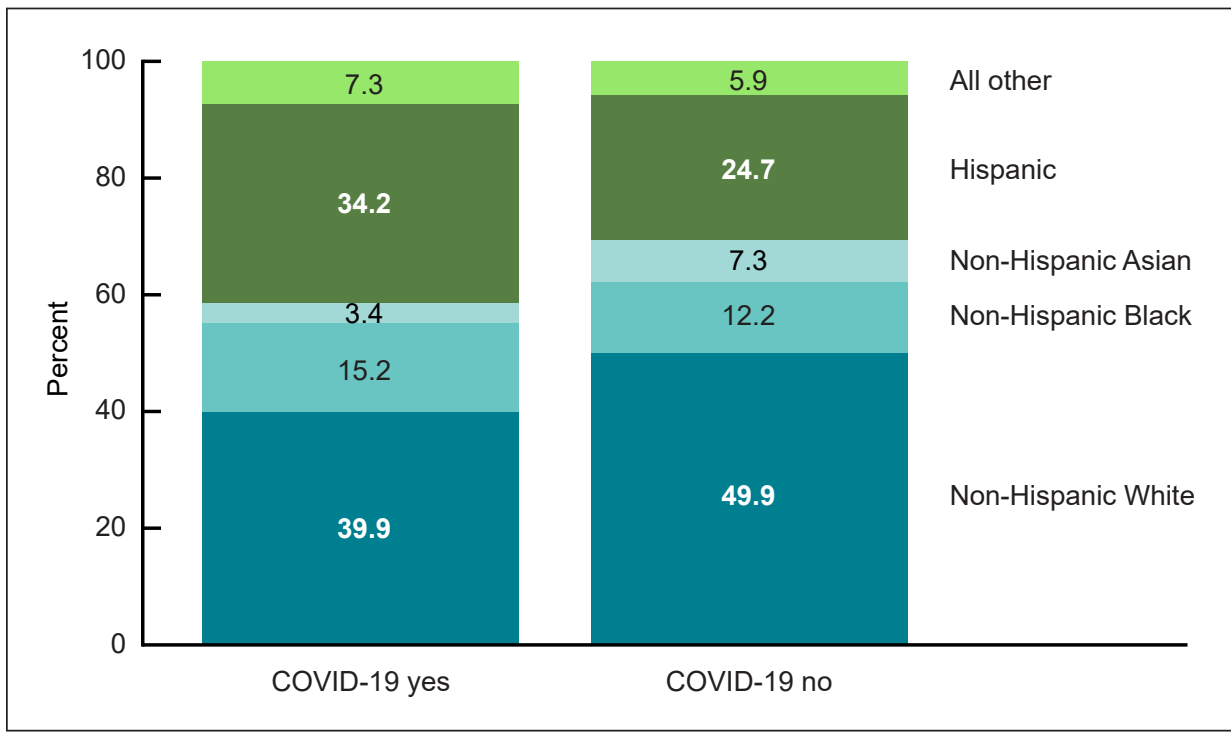

NOTES: Reporting area includes Alabama, Alaska, Arkansas, California, District of Columbia, Idaho, Maine, Maryland, New Hampshire, North Dakota, Ohio, Oklahoma, Oregon, Tennessee, and West Virginia. COVID-19 yes includes presumed or confirmed cases. All other includes births to race and Hispanic-origin groups not shown separately, such as non-Hispanic American Indian or Alaska Native, non-Hispanic Native Hawaiian or Other Pacific Islander, non-Hispanic multiple race, and Hispanic origin not stated. SOURCE: National Center for Health Statistics, National Vital Statistics System, Natality.

Figure 4. Intensive care unit admission rates, by maternal COVID-19 status and race and Hispanic origin: 14 states and the District of Columbia, April 2020-April 2021

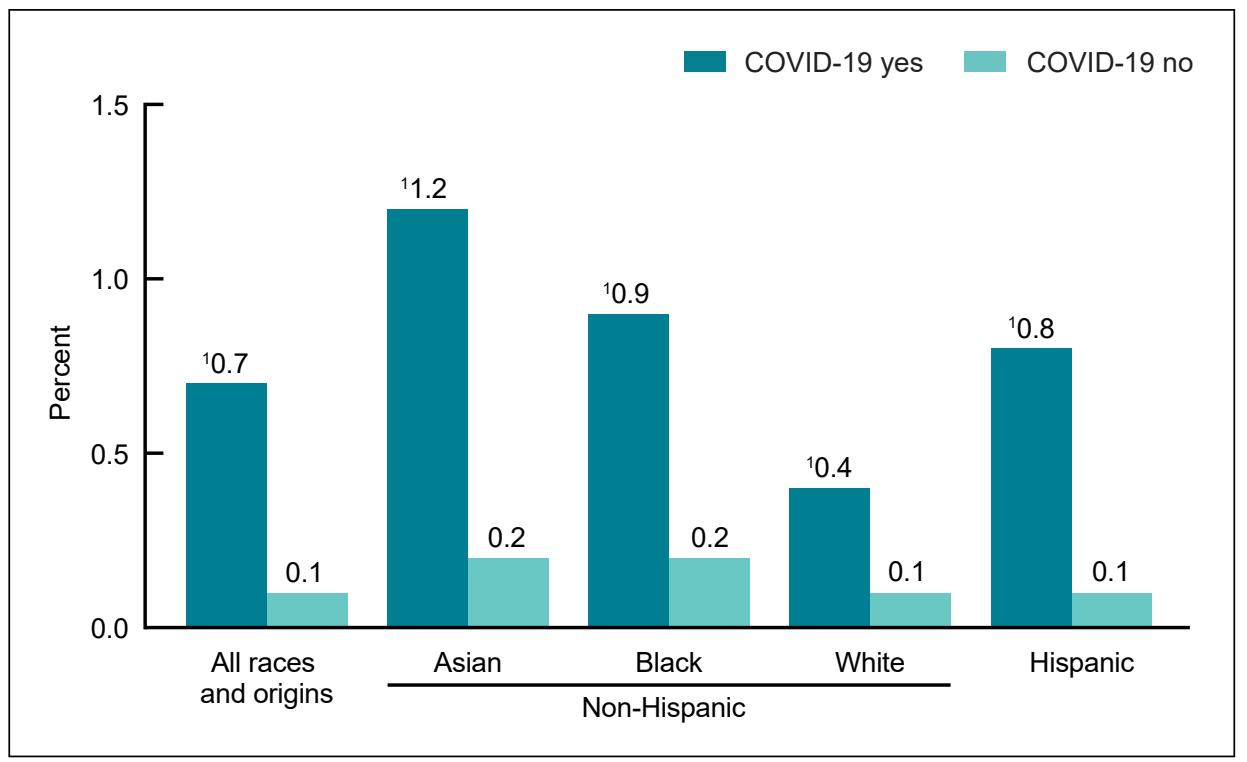

'Significantly higher than COVID-19 no $(p<0.05)$.

NOTES: Reporting area includes Alabama, Alaska, Arkansas, California, District of Columbia, Idaho, Maine, Maryland, New Hampshire, North Dakota, Ohio, Oklahoma, Oregon, Tennessee, and West Virginia. COVID-19 yes includes presumed or confirmed cases. SOURCE: National Center for Health Statistics, National Vital Statistics System, Natality.

Hispanic-origin groups. Private insurance was more likely to be the source of payment for mothers without COVID-19 for all groups except non-Hispanic White women.

\section{Pregnancy outcomes}

\section{ICU admission}

- Overall, within the 15-jurisdiction reporting area, the ICU admission rate was $0.7 \%$ among mothers with COVID-19 and 0.1\% among mothers without COVID-19 (Table 2, Figure 4).
- Although relative differences varied by group, similar patterns were observed for each of the maternal age, education, and race and Hispanic-origin groups. For example, the rate of ICU admission for mothers aged 25-29 with COVID-19 was $0.6 \%$ compared with $0.1 \%$ for mothers without COVID-19. Among mothers with a bachelor's degree or higher, $0.4 \%$ of mothers with COVID-19 were admitted to an ICU compared with $0.1 \%$ of mothers without COVID-19; the ICU rate for Hispanic mothers with COVID-19 was $0.8 \%$ compared with $0.1 \%$ for mothers without COVID-19.

- Among mothers for whom Medicaid was the source of payment for the delivery, $0.8 \%$ of mothers with COVID-19 were admitted to an ICU compared with $0.2 \%$ of mothers without COVID-19. Among mothers for whom private insurance was the source of payment, $0.6 \%$ of mothers with COVID-19 were admitted to an ICU compared with $0.1 \%$ of mothers without COVID-19.

\section{Preterm birth}

- Overall, the preterm birth rate was $12.2 \%$ among infants born to mothers with COVID-19 and 9.9\% among infants born to mothers without COVID-19 (Table 2, Figure 5).

- Similar patterns by COVID-19 status were observed for each age, education, and race and Hispanic-origin group. For example, the preterm birth rate for mothers aged 25-29 with COVID-19 was $11.7 \%$ compared with 9.3\% for those without COVID-19. Among mothers with a bachelor's degree or higher, the preterm rate was $9.7 \%$ for births to mothers with COVID-19 compared with $8.0 \%$ for births to mothers without COVID-19; the preterm rate for births to Hispanic mothers with COVID-19 was $11.8 \%$ compared with $9.2 \%$ for mothers without COVID-19.

- Among mothers for whom Medicaid was the source of payment, the preterm birth rate was $13.3 \%$ for mothers with COVID-19 compared 
Figure 5. Preterm birth rates, by maternal COVID-19 status and age: 14 states and the District of Columbia, April 2020-April 2021

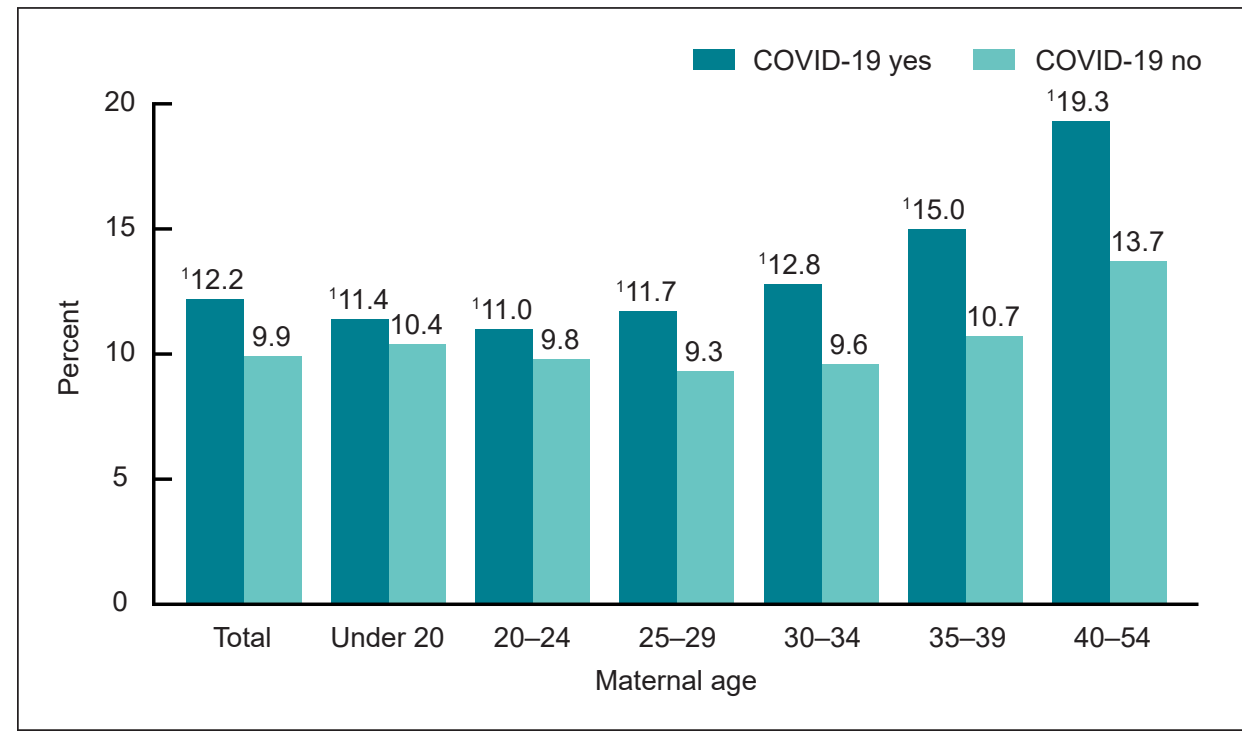

'Significantly higher than COVID-19 no $(p<0.05)$.

NOTES: Preterm is less than 37 weeks of gestation. Reporting area includes Alabama, Alaska, Arkansas, California, District of Columbia, Idaho, Maine, Maryland, New Hampshire, North Dakota, Ohio, Oklahoma, Oregon, Tennessee, and West Virginia. COVID-19 yes includes presumed and confirmed cases.

SOURCE: National Center for Health Statistics, National Vital Statistics System, Natality.

with $11.3 \%$ for mothers without COVID-19. Among mothers with private insurance, the preterm rate was $11.4 \%$ for births to mothers with COVID-19 compared with $8.9 \%$ for births to mothers without COVID-19.

\section{Low birthweight}

- In the 15-jurisdiction reporting area, the rate of LBW in infants born to mothers with COVID-19 was 9.0\% compared with $7.9 \%$ for infants born to mothers without COVID-19 (Table 2).

- Similar patterns by maternal COVID-19 status were seen for all age, education, and race and Hispanic-origin groups. For example, the rate of LBW for mothers aged 25-29 with COVID-19 was 8.5\% compared with $7.5 \%$ for mothers without COVID-19. Among infants born to mothers with a bachelor's degree or higher with COVID-19, $7.1 \%$ were LBW compared with $6.3 \%$ of infants of mothers without COVID-19; the LBW rate for births to Hispanic mothers with COVID-19 was $8.1 \%$ compared with $6.8 \%$ for mothers without COVID-19.
- LBW levels in infants born to mothers for whom Medicaid was the source of payment for the delivery were not significantly different by maternal COVID-19 status (9.8\% for mothers with COVID-19 compared with $9.5 \%$ for mothers without COVID-19). Among mothers for whom private insurance was the source of payment, $8.3 \%$ of infants born to mothers with COVID-19 were LBW compared with $6.9 \%$ of infants born to mothers without COVID-19.

\section{NICU admission}

- Overall, $10.5 \%$ of infants born to mothers with COVID-19 were admitted to a NICU compared with $8.8 \%$ of infants of mothers who did not have COVID-19 (Table 2).

- Differences in NICU admission rates were seen for infants born to mothers with and without COVID-19 for each of the age, education, and race and Hispanic-origin groups. For example, the NICU admission rates for infants born to mothers aged 25-29 with and without COVID-19 were 9.8\% and $8.4 \%$, respectively. Among mothers with a bachelor's degree or higher, $9.3 \%$ of infants of mothers with COVID-19 were admitted to an ICU compared with $7.6 \%$ of infants of mothers without COVID-19; the NICU rate for infants born to Hispanic mothers with COVID-19 was 9.9\% compared with $7.6 \%$ for infants born to mothers without COVID-19.

- When Medicaid was the source of payment for the delivery, $11.5 \%$ of infants born to mothers with COVID-19 were admitted to a NICU compared with $9.8 \%$ of infants of mothers without COVID-19. When private insurance was the source of payment, the percentage of infants admitted to a NICU was $9.7 \%$ among mothers with COVID-19 and 8.0\% among mothers without COVID-19.

\section{Discussion}

In the 15-jurisdiction reporting area from April 2020 through April 2021, mothers reported to have had COVID-19 during pregnancy tended to be younger and have lower educational levels than mothers who did not have COVID-19. Mothers with COVID-19 were also more likely to be Hispanic or non-Hispanic Black and to have Medicaid as the principal source of payment for the delivery. Overall, and generally among each of the age, education, source of payment, and race and Hispanic-origin groups studied, mothers in the 15 -jurisdiction reporting area who had COVID-19 during pregnancy were more likely to be admitted to an ICU, and to have an infant born preterm, LBW, and admitted to a NICU than mothers who did not have COVID-19.

These findings are consistent with the findings of several other reports (5-8), including those of the Surveillance for Emerging Threats to Mothers and Babies Network (SET-NET), another CDC source of information on maternal COVID-19 (9). A study using SET-NET data suggested that pregnant women with SARS-CoV-2 infection are at increased risk of severe illness compared with nonpregnant women, and that pregnant women with SARS-CoV-2 infection may be at risk of preterm delivery (9). 
The maternal COVID-19 data presented in this report are subject to certain limitations. The data are not representative of all mothers giving birth in the United States during the study period. Given that the incidence of COVID-19 varies substantially by state and by reporting period, and that the 15 reporting jurisdictions are not a random sample of states (see note on the disproportionate representation of California births in the Methods section), results may vary over time and geography. The lack of standardization of the process for collecting COVID-19 data across the reporting jurisdictions may have also impacted the representativeness and completeness of the data. Some jurisdictions included only confirmed cases, while others reported presumed or confirmed COVID-19, and less severe or nonsymptomatic cases of COVID-19 may not have been reported. Among the states that report only confirmed cases of maternal COVID-19, there may be an undercount of mothers with COVID-19 and an overcount of mothers without COVID-19. As a result, differences in maternal characteristics and infant outcomes between the COVID-19 and non-COVID-19 groups may be biased. The information on COVID-19 cases shown may not include all cases of maternal COVID-19 that occurred in the reporting areas during April 2020-April 2021. Information on some cases occurring later in the study period may not have been provided to the state before June 17, 2021, while information on cases occurring earlier in the study period may not have been reported due to lack of widespread testing in early 2020. Differences in outcomes observed between mothers with and without COVID-19 during pregnancy may be influenced by differences in maternal demographic and health characteristics not accounted for in this analysis or factors not captured on the birth certificate.

Although limited information is available on the quality of data of other infections reported on the birth certificate, underreporting of specific infections has been observed in some jurisdictions (10); this may also have impacted the level of reporting of COVID-19 information. Despite these limitations, the maternal COVID-19 data linked with birth certificate data presented in this report have advantages over other data sources. One is the ability to directly compare maternal and infant characteristics and outcomes between women with and without COVID-19 during pregnancy, whereas other data sources collect information only on COVID-19 cases $(6,9)$. Another is the quality and completeness of information on maternal race and Hispanic origin, which is reported directly by the mother around the time of delivery and allows for more detailed analysis of smaller population groups; complete and detailed information on maternal race and ethnicity is typically not possible from other data sources. An additional strength of this report is that data collected on the U.S. Standard Certificate of Live Birth, which include all demographic characteristics and outcome measures in this report, are collected in a consistent manner across jurisdictions (11).

This report demonstrates that vital statistics birth data can serve as a unique and valuable source of information on new and emerging issues affecting maternal and newborn health. Ongoing bimonthly updates (2), and additional analysis of these data should further enhance understanding of the impact of COVID-19 on pregnancy.

\section{References}

1. National Center for Health Statistics. 2003 revisions of the U.S. Standard Certificates of Live Birth and Death and Fetal Death Report. Available from: https://www.cdc.gov/nchs/ nvss/vital_certificate_revisions.htm.

2. Osterman MJK, Valenzuela CP, Martin JA. Maternal and infant characteristics among women with confirmed or presumed cases of Coronavirus disease (COVID-19) during pregnancy. National Center for Health Statistics. National Vital Statistics System. 2021 Available from: https://www.cdc.gov/nchs/ covid19/technical-linkage.htm.

3. National Center for Health Statistics. Provisional estimates for selected maternal and infant outcomes by month, 2018-2021. Available from: https://www.cdc.gov/nchs/covid19/ technical-notes-outcomes.htm.

4. National Center for Health Statistics. Guide to completing the facility worksheets for the Certificate of Live Birth and Report of Fetal Death (2003 revision). 2019. Available from: https:// www.cdc.gov/nchs/data/dvs/ GuidetoCompleteFacilityWks.pdf.

5. Villar J, Ariff S, Gunier RB, Thiruvengadam R, Rauch S, Kholin A, et al. Maternal and neonatal morbidity and mortality among pregnant women with and without COVID-19: The INTERCOVID Multinational Cohort Study. JAMA Pediatr 175(8):817-26. 2021. Available from: https://jamanetwork. com/journals/jamapediatrics/ fullarticle/2779182.

6. Zambrano LD, Ellington S, Strid P, Galang RR, Oduyebo T, Tong VT, et al. Update: Characteristics of symptomatic women of reproductive age with laboratory-confirmed SARS-CoV-2 infection by pregnancy status-United States, January 22-October 3, 2020. MMWR Morb Mortal Wkly Rep 69(44):1641-7. 2020. Available from: https://www. cdc.gov/mmwr/volumes/69/wr/ mm6944e3.htm.

7. Wei SQ, Bilodeau-Bertrand M, Liu S, Auger N. The impact of COVID-19 on pregnancy outcomes: A systematic review and metaanalysis. CMAJ 193(16):E540-8. 2021. Available from: https://www. ncbi.nlm.nih.gov/pmc/articles/ PMC8084555/.

8. Allotey J, Stallings E, Bonet M, Yap M, Chatterjee S, Kew T, et al. Clinical manifestations, risk factors, and maternal and perinatal outcomes 
of coronavirus disease 2019 in pregnancy: Living systematic review and meta-analysis. BMJ 2020 370:m3320. 2021. Available from: https://www.bmj.com/content/ bmj/370/bmj.m3320.full.pdf.

9. Woodworth KR, Olsen EO, Neelam V, Lewis EL, Galang RR, Oduyebo T, et al. Birth and infant outcomes following laboratoryconfirmed SARS-CoV-2 infection in pregnancy-SET-NET, 16 jurisdictions, March 29-October 14, 2020. MMWR Morb Mortal Wkly Rep 69(44):1635-40. 2020. Available from: https://www. cdc.gov/mmwr/volumes/69/wr/ mm6944e2.htm.

10. Gregory ECW, Ely DM. Trends and characteristics of sexually transmitted infections during pregnancy: United States, 2016-2018. National Vital Statistics Reports; vol 69 no 3. Hyattsville, MD: National Center for Health Statistics. 2020. Available from: https://www.cdc.gov/nchs/data/nvsr/ nvsr69/nvsr69-03-508.pdf.

11. National Center for Health Statistics. User guide to the 2019 natality public use file. Hyattsville, MD. Available from: https:// www.cdc.gov/nchs/data_access/ Vitalstatsonline.htm.

\section{List of Detailed Tables}

\section{Report tables}

1. Presumed or confirmed cases of maternal COVID-19 during pregnancy, by selected maternal characteristics and race and Hispanic origin of the mother: 14 states and the District of Columbia, April 2020-April 2021. . . . . . . . . .

2. Births by maternal COVID-19 status, by selected maternal characteristics and pregnancy outcomes: 14 states and the District of Columbia, April 2020-April 2021 . . . . . . . . . . 


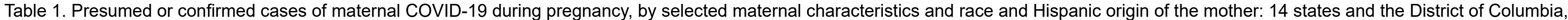
April 2020-April 2021

\begin{tabular}{|c|c|c|c|c|c|c|c|c|c|c|}
\hline \multirow[b]{2}{*}{ Characteristic } & \multicolumn{2}{|c|}{ Total $^{1}$} & \multicolumn{2}{|c|}{ Non-Hispanic White ${ }^{2}$} & \multicolumn{2}{|c|}{ Non-Hispanic Black ${ }^{2}$} & \multicolumn{2}{|c|}{ Non-Hispanic Asian ${ }^{2}$} & \multicolumn{2}{|c|}{ Hispanic $^{3}$} \\
\hline & $\begin{array}{l}\text { COVID-19 } \\
\text { yes }^{4}\end{array}$ & $\begin{array}{c}\text { COVID-19 } \\
\text { no }\end{array}$ & $\begin{array}{l}\text { COVID-19 } \\
\text { yes }^{4}\end{array}$ & $\begin{array}{c}\text { COVID-19 } \\
\text { no }\end{array}$ & $\begin{array}{l}\text { COVID-19 } \\
\text { yes }^{4}\end{array}$ & $\begin{array}{c}\text { COVID-19 } \\
\text { no }\end{array}$ & $\begin{array}{l}\text { COVID-19 } \\
\text { yes }^{4}\end{array}$ & $\begin{array}{c}\text { COVID-19 } \\
\text { no }\end{array}$ & $\begin{array}{l}\text { COVID-19 } \\
\text { yes }^{4}\end{array}$ & $\begin{array}{c}\text { COVID-19 } \\
\text { no }\end{array}$ \\
\hline & \multicolumn{10}{|c|}{ Number } \\
\hline \multirow[t]{2}{*}{ Total. } & 31,806 & 901,304 & 12,686 & 449,447 & 4,833 & 110,223 & 1,097 & 65,628 & 10,872 & 222,205 \\
\hline & \multicolumn{10}{|c|}{ Percent distribution } \\
\hline COVID-19 cases $^{5}$ & 100.0 & & 39.9 & $\ldots$ & 15.2 & & 3.4 & & 34.2 & \\
\hline Non-COVID-19 cases $^{5}$ & $\ldots$ & 100.0 & $\ldots$ & 49.9 & $\ldots$ & 12.2 & $\ldots$ & 7.3 & $\ldots$ & 24.7 \\
\hline \multicolumn{11}{|l|}{ Age of mother } \\
\hline Total $^{5}$ & 100.1 & 100.0 & 100.0 & 99.9 & 100.0 & 100.1 & 99.9 & 100.0 & 100.0 & 100.0 \\
\hline Under 20. & 5.5 & 4.3 & 3.7 & 3.4 & 6.5 & $\dagger 6.7$ & 1.2 & 0.4 & 7.4 & 5.8 \\
\hline$\ldots \ldots \ldots \ldots \ldots \ldots$ & 22.5 & 18.2 & 20.4 & 17.0 & 25.3 & 23.7 & 8.9 & 4.2 & 24.3 & 21.5 \\
\hline $25-29 \ldots \ldots \ldots \ldots$ & 30.6 & 27.9 & 32.6 & 28.4 & 31.5 & 29.1 & 24.2 & 18.5 & 29.0 & $\dagger 29.3$ \\
\hline$\ldots \ldots \ldots \ldots \ldots \ldots$ & 25.7 & 29.6 & 28.7 & 31.7 & 23.1 & $\dagger 24.2$ & 36.1 & 41.1 & 22.5 & 25.2 \\
\hline $35-39 \ldots \ldots \ldots \ldots \ldots \ldots \ldots \ldots \ldots$ & 12.8 & 16.2 & 12.3 & 16.1 & 10.7 & 13.0 & 23.8 & 28.8 & 13.2 & 14.4 \\
\hline 40 and over & 3.0 & 3.8 & 2.3 & 3.3 & 2.9 & 3.4 & 5.7 & $\dagger 7.0$ & 3.6 & $\dagger 3.8$ \\
\hline \multicolumn{11}{|l|}{ Educational attainment } \\
\hline Total $^{5,6}$ & 100.0 & 100.0 & 100.0 & 100.0 & 100.1 & 100.0 & 100.0 & 100.1 & 99.9 & 100.0 \\
\hline Less than high school. . . . . . . . . . . . . . & 16.8 & 11.4 & 6.0 & $\dagger 7.0$ & 11.4 & $\dagger 11.3$ & 9.9 & 3.2 & 33.2 & 23.0 \\
\hline High school diploma or GED $\ldots \ldots \ldots \ldots \ldots$ & 30.9 & 26.8 & 24.8 & 23.1 & 39.8 & 36.8 & 20.9 & 10.8 & 34.5 & 33.1 \\
\hline Some college $\ldots \ldots \ldots \ldots \ldots \ldots \ldots \ldots$ & 21.1 & 20.0 & 21.2 & 18.9 & 25.6 & $\dagger 25.4$ & 14.7 & 10.1 & 19.1 & 21.7 \\
\hline Associate's degree $\ldots \ldots \ldots \ldots \ldots \ldots \ldots$ & 8.2 & $\dagger 8.0$ & 11.3 & 9.0 & 8.2 & 7.4 & 7.6 & $\dagger 6.2$ & 4.7 & 6.6 \\
\hline Bachelor's degree or higher. . . . . . . . . . . & 23.0 & 33.8 & 36.7 & 42.0 & 15.1 & 19.1 & 46.9 & 69.8 & 8.4 & 15.6 \\
\hline \multicolumn{11}{|l|}{ Source of payment } \\
\hline$\ldots \ldots \ldots \ldots \ldots \ldots \ldots \ldots$ & 100.0 & 100.0 & 100.0 & 100.0 & 100.0 & 100.0 & 100.0 & 100.0 & 100.0 & 100.0 \\
\hline$\ldots \ldots \ldots \ldots \ldots \ldots \ldots \ldots$ & 51.4 & 41.4 & 32.3 & 30.9 & 67.2 & 62.7 & 37.3 & 19.3 & 67.7 & 57.8 \\
\hline Private insurance $\ldots \ldots \ldots \ldots \ldots \ldots \ldots$ & 43.0 & 51.7 & 63.2 & 62.0 & 29.6 & 32.6 & 56.6 & 74.9 & 24.5 & 34.8 \\
\hline Other $^{7} \ldots \ldots \ldots \ldots \ldots \ldots \ldots \ldots \ldots \ldots$ & 5.6 & 6.9 & 4.5 & 7.1 & 3.2 & 4.7 & 6.1 & $\dagger 5.8$ & 7.8 & $\dagger 7.4$ \\
\hline
\end{tabular}

Category not applicable

Includes births to race and Hispanic-origin groups not shown separately, such as non-Hispanic American Indian or Alaska Native, non-Hispanic Native Hawaiian or Other Pacific Islander, non-Hispanic multiple race, and Hispanic origin not stated.

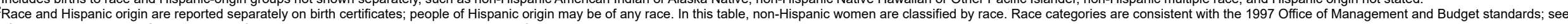
eference 1 in this report. Single race is defined as only one race reported on the birth certificate.

Includes all people of Hispanic origin of any race; see reference 1 in this report.

Confirmed or presumed COVID-19 during pregnancy. Only confirmed cases are included for California, Maryland, North Dakota, Ohio, and Tennessee.

May not add to 100 due to rounding.

cludes women who may not have had time to complete their education.

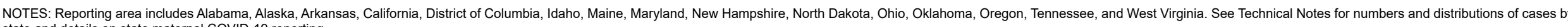
SORCE:

SOURCE: National Center for Health Statistics, National Vital Statistics System, Natality. 
Vital Statistics Surveillance Report

Table 2. Births by maternal COVID-19 status, by selected maternal characteristics and pregnancy outcomes: 14 states and the District of Columbia, April $2020-$ April 2021

\begin{tabular}{|c|c|c|c|c|c|c|c|c|c|c|c|c|}
\hline \multirow[b]{2}{*}{ Characteristic } & \multicolumn{3}{|c|}{ ICU admission ${ }^{1}$} & \multicolumn{3}{|c|}{ Preterm $^{2}$} & \multicolumn{3}{|c|}{ Low birthweight ${ }^{3}$} & \multicolumn{3}{|c|}{ NICU admission ${ }^{4}$} \\
\hline & $\begin{array}{l}\text { COVID-19 } \\
\text { yes }^{5} \\
\text { (percent) }\end{array}$ & $\begin{array}{l}\text { COVID-19 } \\
\text { no } \\
\text { (percent) }\end{array}$ & $\begin{array}{l}\text { Percent } \\
\text { difference }\end{array}$ & $\begin{array}{l}\text { COVID-19 } \\
\text { yes }^{5} \\
\text { (percent) }^{2}\end{array}$ & $\begin{array}{l}\text { COVID-19 } \\
\text { no } \\
\text { (percent) }\end{array}$ & $\begin{array}{l}\text { Percent } \\
\text { difference }\end{array}$ & $\begin{array}{l}\text { COVID-19 } \\
\text { yes }^{5} \\
\text { (percent) }\end{array}$ & $\begin{array}{l}\text { COVID-19 } \\
\text { no } \\
\text { (percent) }\end{array}$ & $\begin{array}{l}\text { Percent } \\
\text { difference }\end{array}$ & $\begin{array}{l}\text { COVID-19 } \\
\text { yes }^{5} \\
\text { (percent) }^{2}\end{array}$ & $\begin{array}{l}\text { COVID-19 } \\
\text { no } \\
\text { (percent) }\end{array}$ & $\begin{array}{c}\text { Percent } \\
\text { difference }\end{array}$ \\
\hline All births. . $\ldots \ldots \ldots \ldots \ldots \ldots \ldots \ldots \ldots$ & 0.7 & 0.1 & 600 & 12.2 & 9.9 & 23 & 9.0 & 7.9 & 14 & 10.5 & 8.8 & 19 \\
\hline \multicolumn{13}{|l|}{ Age of mother } \\
\hline Under $20 \ldots \ldots \ldots \ldots \ldots \ldots \ldots \ldots \ldots \ldots$ & 0.5 & 0.1 & 400 & 11.4 & 10.4 & $\dagger 10$ & 10.0 & 10.0 & †0 & 9.8 & 8.9 & $\dagger 10$ \\
\hline $25-29$. & 0.6 & 0.1 & 500 & 11.7 & 9.3 & 26 & 8.5 & 7.5 & 13 & 9.8 & 8.4 & 17 \\
\hline 30-34. . & 0.7 & 0.2 & 250 & 12.8 & 9.6 & 33 & 8.9 & 7.4 & 20 & 10.9 & 8.5 & 28 \\
\hline 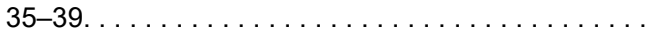 & 1.4 & 0.2 & 600 & 15.0 & 10.7 & 40 & 10.7 & 8.1 & 32 & 13.6 & 9.4 & 45 \\
\hline $40-54 \ldots \ldots$ & 1.7 & 0.4 & 325 & 19.3 & 13.7 & 41 & 13.4 & 10.6 & 26 & 18.2 & 11.9 & 53 \\
\hline \multicolumn{13}{|l|}{ Educational attainment } \\
\hline Less than high school $\ldots \ldots \ldots \ldots \ldots \ldots \ldots \ldots$ & 0.9 & 0.2 & 350 & 13.2 & 11.6 & 14 & 8.9 & 9.5 & $\dagger-6$ & 11.0 & 9.4 & 17 \\
\hline High school diploma or GED . . . . & 0.6 & 0.2 & 200 & 12.8 & 10.9 & 17 & 10.1 & 9.1 & 11 & 10.8 & 9.3 & 16 \\
\hline Some college. . & 0.8 & 0.1 & 700 & 13.5 & 10.4 & 30 & 9.9 & 8.2 & 21 & 11.5 & 9.2 & 25 \\
\hline \multicolumn{13}{|l|}{ Race and Hispanic origin } \\
\hline Non-Hispanic White ${ }^{6}$ & 0.4 & 0.1 & 300 & 10.7 & 9.2 & 16 & 7.4 & 6.9 & 7 & 9.6 & 8.6 & 12 \\
\hline Non-Hispanic Black ${ }^{6}$ & 0.9 & 0.2 & 350 & 16.4 & 14.3 & 15 & 14.8 & 14.1 & $\dagger 5$ & 14.0 & 12.2 & 15 \\
\hline Non-Hispanic Asian ${ }^{6}$ & 1.2 & 0.2 & 500 & 10.4 & 8.7 & 20 & 8.4 & 8.3 & $\dagger 1$ & 9.6 & 7.1 & 35 \\
\hline Hispanic $^{7} \ldots \ldots \ldots \ldots \ldots \ldots \ldots \ldots \ldots$ & 0.8 & 0.1 & 700 & 11.8 & 9.2 & 28 & 8.1 & 6.8 & 19 & 9.9 & 7.6 & 30 \\
\hline \multicolumn{13}{|l|}{ Source of payment } \\
\hline Medicaid & 0.8 & 0.2 & 300 & 13.3 & 11.3 & 18 & 9.8 & 9.5 & $\dagger 3$ & 11.5 & 9.8 & 17 \\
\hline Private insurance. . & 0.6 & 0.1 & 500 & 11.4 & 8.9 & 28 & 8.3 & 6.9 & 20 & 9.7 & 8.0 & 21 \\
\hline
\end{tabular}

$\dagger$ Not significant at $p<0.05$

${ }^{1}$ Admission to an intensive care unit.

${ }^{2}$ Less than 37 completed weeks of gestation. Gestational age is measured in completed weeks; based on the obstetric estimate of gestation.

${ }^{3}$ Less than 2,500 grams.

Admission to a neonatal intensive care unit.

Confirmed or presumed cases of maternal COVID-19.

on birth certificates; people of Hispanic origin may be of any race. In this table, non-Hispanic women are classified by race. Race categories are consistent with the 1997 Office of Management and Budget standards; see as only one race reported on the birth certificate.

NOTE: Reporting area includes Alabama, Alaska, Arkansas, California, District of Columbia, Idaho, Maine, Maryland, New Hampshire, North Dakota, Ohio, Oklahoma, Oregon, Tennessee, and West Virginia.

SOURCE: National Center for Health Statistics, National Vital Statistics System, Natality. 


\section{Acknowledgments}

This report was made possible due to the cooperation of 15 vital statistics jurisdictions: Alabama, Alaska, Arkansas, California, District of Columbia, Idaho, Maine, Maryland, New Hampshire, North Dakota, Ohio, Oklahoma, Oregon, Tennessee, and West Virginia.

\section{Suggested citation}

Martin JA, Osterman MJK, Valenzuela CP. Maternal and infant characteristics and outcomes among women with confirmed or presumed COVID-19 during pregnancy: 14 states and the District of Columbia. Vital Statistics Rapid Release; no 17. Hyattsville, MD: National Center for Health Statistics. December 2021. DOI: https://dx.doi. org/10.15620/cdc:111693.

\section{Copyright information}

All material appearing in this report is in the public domain and may be reproduced or copied without permission; citation as to source, however, is appreciated.

\section{National Center for Health Statistics}

Brian C. Moyer, Ph.D., Director

Amy M. Branum, Ph.D., Associate

Director for Science

\section{Division of Vital Statistics}

Steven Schwartz, Ph.D., Director

Isabelle Horon, Dr.P.H., Acting Associate

Director for Science 